\title{
А.М. Кориков
}

\section{Покоритель вершин науки и техники: к 85-летию Владимира Петровича Тарасенко}

\begin{abstract}
Посвящается Владимиру Петровичу Тарасенко (09.12.1934 - 27.11.2003).
Основная область научных интересов В.П. Тарасенко - автоматическое и автоматизированное управление сложными системами. Он первым в СССР предложил принципы построения и развил теорию корреляционноэкстремальных навигационных систем (КЭНС), использующих радиолокационные карты местности и нашедших применение в управлении летательными аппаратами, судами, наземным транспортом. За разработку принципов построения и теории КЭНС В.П. Тарасенко в 1993 г. удостоен Государственной премии РФ в области науки и техники. В.П. Тарасенко принимал активное участие в создании автоматизированной системы управления хозяйством Томской области (АСУ ТО), был главным конструктором АСУ ТО. Под его руководством велись работы по автоматизации технологических процессов перекачки нефти по нефтепроводам Сибири и создавались автоматизированные системы информационного обеспечения добычи нефти и многие другие автоматические и автоматизированные системы управления.

Ключевые слова: В.П. Тарасенко, корреляционно-экстремальные навигационные системы, системы автоматического управления, автоматизированные системы управления.
\end{abstract}

doi: $10.21293 / 1818-0442-2019-22-4-119-124$

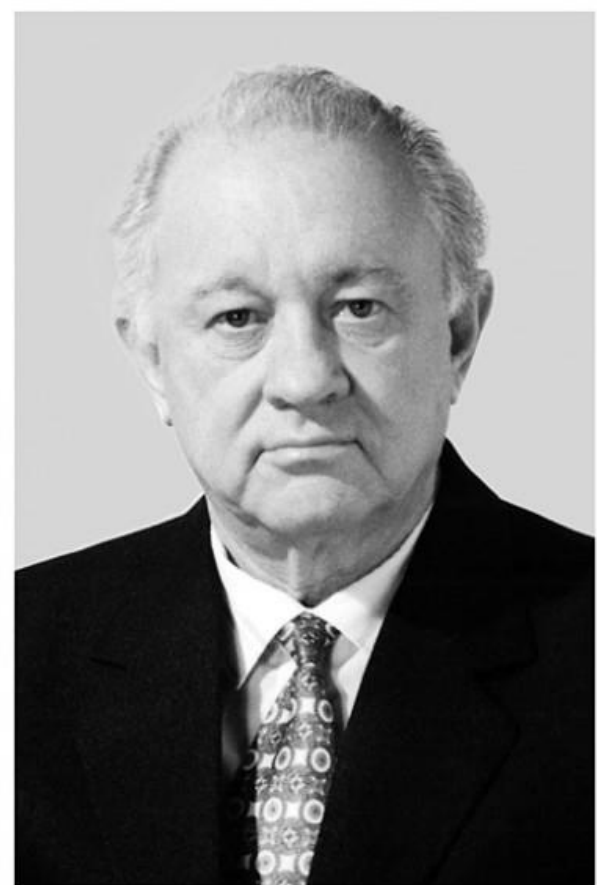

Тарасенко Владимир Петрович, почетный гражданин г. Томска

9 декабря 2019 г. исполнилось бы 85 лет Владимиру Петровичу Тарасенко. Он ушел из жизни 27 ноября 2003 г. В этот день, в четверг, в НИИАЭМ при ТУСУРе проходило заседание совета по защите диссертаций в области автоматики и информатики, бессменным председателем которого Владимир Петрович был многие годы с момента его открытия в 1985 г. Для нас, коллег, сотрудников и учеников Владимира Петровича, известие об этой утрате стало полной неожиданностью: находясь на лечении в госпитальной клинике им. А.Г. Савиных СибГМУ, он общался со многими из нас. Автор этих строк посетил Владимира Петровича в его больничной палате накануне, 26 ноября 2003 г., была вера в успешный исход предстоящей операции. Владимир Петрович ушел из жизни, но остался в памяти живым, целеустремленным и интересным собеседником.

В.П. Тарасенко не дожил до своего 85-летия, а память о нем живет: его сотрудники и ученики посвящают ему свои книги $[1,2]$, в ТУСУРе на кафедре КСУП его именем названа учебная аудитория, на здании научно-исследовательского института автоматики и электромеханики (НИИАЭМ) при ТУСУРе в память о В.П. Тарасенко открыта мемориальная доска, решением Томской городской думы № 659 от 07.06.2004 Владимиру Петровичу Тарасенко присвоено звание «Почётный гражданин Томска».

Заслуги В.П. Тарасенко признаны как в нашей стране, так и за её пределами. Он являлся действительным членом Международной академии наук высшей школы и Российской инженерной академии с момента основания этих академий, лауреатом Государственной премии РФ в области науки и техники за разработку принципов построения и теории корреляционно-экстремальных сверхточных систем навигации и наведения (1993), лауреатом конкурсов Томской области в сфере образования и науки (1996, 1999), заслуженным деятелем науки и техники РСФСР (1991). В.П. Тарасенко был награжден орденами «Знак Почета» (1986), Дружбы (2000), медалями «За доблестный труд. В ознаменование 100-летия со дня рождения Владимира Ильича Ленина» (1970), «За освоение недр и развитие нефтегазового комплекса Западной Сибири» (1980).

Сегодня благодаря Интернету в сети можно найти много интересного практически о любом человеке и тем более о Владимире Петровиче Тарасенко, но все-таки хорошим книгам всегда нужно отдавать предпочтение. Среди них отметим биографические справочники $[3,4]$, которые содержат биогра- 
фии многих томских ученых, и в их числе, конечно, биографию В.П. Тарасенко. Уникальную книгу [5] издали сокурсники В.П. Тарасенко по радиофизическому факультету (РФФ) Томского государственного университета (ТГУ). В этой книге на с. 167-172 описаны не только научные достижения В.П. Тарасенко, но его школьные и студенческие годы, его песни на музыку известных шлягеров.

В памяти всплывает много эпизодов, связанных с В.П. Тарасенко. Если бы нашлось «бойкое перо», то из этих эпизодов вполне можно сочинить роман для серии ЖЗЛ (жизнь замечательных людей). Кратко изложу две истории. В этих историях проявляется личность Владимира Петровича Тарасенко как Ученого и как Человека.

Одной из этих историй уже более 50 лет. В 1967-1970 гг. я был аспирантом ТГУ. Мой научный руководитель по аспирантуре Геннадий Алексеевич Медведев и Владимир Петрович Тарасенко в тот период совместно руководили хоздоговорной НИР (шифр НИР «Сова»). Хоздоговор был с одним из красноярских «почтовых ящиков» (так в те годы назывались закрытые (режимные) НИИ и предприятия). Для выполнения хоздоговора наши руководители создали научную группу из аспирантов ТГУ и сотрудников лаборатории адаптивных оптимальных систем (ЛАОС) Сибирского физико-технического института (СФТИ) им. акад. В.Д. Кузнецова при ТГУ. В сентябре 1967 г. наша научная группа из четырех человек во главе с В.П. Тарасенко (в это время он был заместителем директора СФТИ по научной работе) была отправлена в командировку в г. Красноярск для выполнения конкретных заданий по НИР «Сова». В наши командировочные сроки попали суббота и воскресенье - на нашем «почтовом ящике» это были выходные дни, и В.П. Тарасенко предложил всей нашей научной группе совершить двухдневный поход на Красноярские столбы. Аргументы некоторых из нас, в частности мои, о том, что мы не взяли с собой в командировку туристическое снаряжение, были отклонены: с помощью своих красноярских друзей Владимир Петрович обеспечил нас этим снаряжением, мне, например, из одежды было выделено трико, а из обуви - галоши (моё последующее скалолазание подтвердило, что резиновые галоши практичнее кроссовок). Итак, в субботу наша туристическая группа отправилась на Красноярские столбы, переночевали в каком-то каменном гроте, а в воскресенье начали покорять столбы.

Прошло уже более 50 лет, но до сих пор во всех деталях вспоминаю наше восхождение на второй столб: впереди всех по каменному лазу полз Владимир Петрович, за ним полз я, и замыкал нашу группу скалолазов Слава Фофонов - сотрудник ЛАОС СФТИ. Он был самым опытным туристом в нашей группе. У Владимира Петровича за спиной на ремне был фотоаппарат, контакт со скалой был таким плотным, что ремень на его груди перетерся о скалу и фотоаппарат с обрывками ремня полетел вниз, задевая при этом членов нашей группы, через неко- торое время мы услышали звук от удара фотоаппарата о подножье скалы и продолжали ползти по почти вертикальному лазу на вершину второго столба.

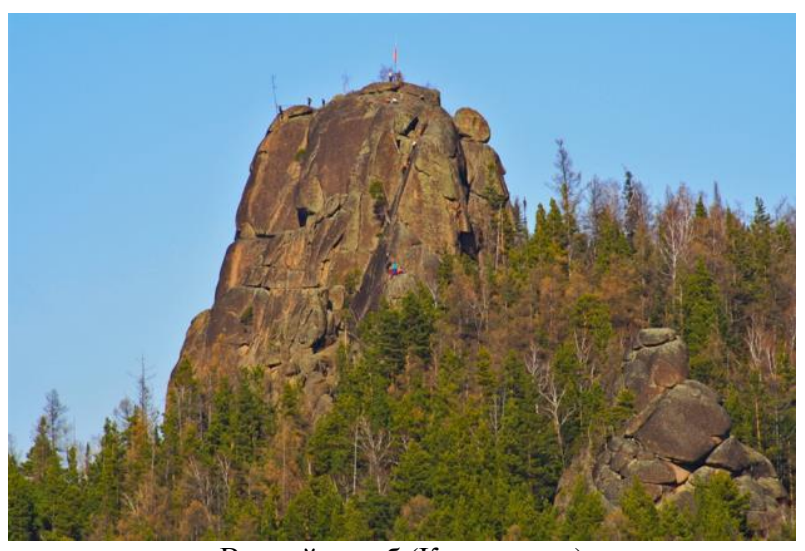

Второй столб (Красноярск)

С вершины второго столба нам открылась панорама необычайной красоты: внизу среди деревьев высились другие столбы, где-то вдали поблескивал Енисей и дымился Красноярск. Восхождение на вершину второго столба было трудным, а спуск оказался не менее трудным и опасным. После спуска со второго столба мы пытались найти хотя бы осколки фотоаппарата, но поиск был безуспешным. Кроме восхождения на вершину второго столба, были и другие яркие впечатления от описываемого двухдневного похода на Красноярские Столбы, совершенного по инициативе и под руководством В.П. Тарасенко. Впоследствии Владимир Петрович неоднократно вспоминал на собраниях нашего коллектива этот поход, вспоминал о том, что он первым забрался на вершину второго столба и наблюдал сверху за тем, как его молодые сотрудники ползли следом за ним на эту вершину и он был готов подать свою руку для помощи тому, кто её попросит. Примерно так же В.П. Тарасенко руководил своими сотрудниками. Это был его фирменный стиль руководства: он ставил перед своими сотрудниками трудные, сложные и казалось бы невыполнимые научнотехнические задачи, и каждый из нас решал их самостоятельно на максимуме своих способностей и возможностей. В этой связи вспоминаю вторую более позднюю историю в период работы В.П. Тарасенко в Томском институте автоматизированных систем управления и радиоэлектроники (ТИАСУР).

Здесь необходима краткая справка. В 1971 г. В.П. Тарасенко основал в Томском институте радиоэлектроники и электронной техники (ТИРиЭТ, затем ТИАСУР) кафедру оптимальных и адаптивных систем управления (ОАСУ) и пригласил работать на кафедру ОАСУ многих своих учеников из СФТИ, ТГУ и ТПИ (из Томского политехнического института пришел на кафедру ОАСУ А.И. Рубан, защитивший ранее под руководством В.П. Тарасенко кандидатскую диссертацию, а впоследствии защитивший при его научной консультации и поддержке докторскую диссертацию). На кафедру ОАСУ при- 
бывали его ученики и из других городов: например, весной 1972 г. из Барнаула приехал А.А. Светлаков (ныне он д.т.н., профессор), у которого В.П. Тарасенко в 1965 г. был руководителем дипломной работы. В 1972 г. по его приглашению и я перешел из ТГУ на кафедру ОАСУ. Заведуя кафедрой ОАСУ, В.П. Тарасенко оставался научным руководителем ЛАОС СФТИ. В те времена кафедра ОАСУ и ЛАОС СФТИ располагались на четвертом этаже главного корпуса ТИАСУРа, позднее СФТИ построил новый лабораторный корпус на ул. Ф. Лыткина, и ЛАОС переехала в этот корпус, но тесное научное сотрудничество кафедры ОАСУ и ЛАОС продолжалось. В 1975 г. ЛАОС должна была завершить НИОКР по разработке опытного образца корреляционноэкстремального координатора (КЭК) для автоматического определения координат движения объектов по радиолокационным картам местности по заданному курсу. Более того, опытный образец КЭК необходимо было передать заказчику для летных испытаний. Однако сроки сдачи НИОКР срывались. Надо было принимать чрезвычайные меры.

В декабре 1975 г. В.П. Тарасенко предложил мне, молодому доценту кафедры ОАСУ, перейти на работу в СФТИ, возглавить ЛАОС, завершить разработку опытного образца КЭК, провести его полевые испытания в окрестностях Томска, передать КЭК заказчику и принять участие в организации и проведении летных испытаний КЭК в ЛИИ (в те времена ЛИИ был режимным объектом, а ныне это всем известный летно-исследовательский институт им. М.М. Громова в Жуковском). В то время на кафедре ОАСУ у меня была небольшая научная группа, с которой я выполнял хоздоговорную НИР (шифр НИР «Кедр»), и в конце декабря 1975 г. мне как руководителю этого хоздоговора необходимо было завершить эту хоздоговорную НИР и сдать её заказчику. Поэтому только в январе 1976 г. я начал вникать в дела ЛАОС и в феврале 1976 г. официально перевелся из ТИАСУРа в СФТИ на должность заведующего ЛАОС, а научным руководителем лаборатории оставался В.П. Тарасенко. Моё сотрудничество с кафедрой ОАСУ продолжилось по учебным делам в форме внешнего совместительства - необходимо было выполнить учебную нагрузку, определенную мне ранее как доценту кафедры. Объем работ по организации и проведению летных испытаний КЭК, описанный выше, даже с позиций сегодняшнего дня впечатляет своей сложностью и трудоемкостью, но трудности были не только технические и технологические, но и финансовые, так как заказчик этой НИОКР приостановил её финансирование, поскольку опытный образец КЭК не был ему передан в установленные сроки. В.П. Тарасенко как научный руководитель ЛАОС, и автор этих строк как заведующий ЛАОС смогли преодолеть эти сложности и трудности: в 1976 г. опытный образец КЭК был доработан и совместно с заказчиком НИОКР в окрестностях Томска были проведены его полевые испытания; в 1977 г. результаты летных испытаний опытного образца КЭК (летающая лаборатория (ЛЛ) ЛИИ с КЭК и группой сотрудников ЛАОС и представителями заказчика НИОКР совершала полеты от Жуковского до Феодосии и обратно) подтвердили точность определения координат движения ЛЛ, заданную техническим заданием на НИОКР. Результаты летных испытаний КЭК в открытой печати не публиковались из-за грифа НИОКР, но руководство СФТИ обязало меня как заведующего ЛАОС изложить это и другие достижения ЛАОС в научно-популярной форме для журнала «Наука и жизнь» к столетию ТГУ. Научнопопулярная статья на эту тему написана и опубликована мной совместно с В.П. Тарасенко [6].

В этой статье читатель может увидеть фотографии КЭК: настройка макета КЭК представлена на c. 88, а на с. 90 - макет КЭК, который демонстрировался на ВДНХ СССР. Фотографии отражают уровень развития элементной базы 70-х гг. прошлого века: это был КЭК второго поколения, вычислительное устройство которого было реализовано на транзисторах, а коррелятор был оптическим. Заметим, что КЭК первого поколения ранее был реализован на радиолампах [7]. То есть история поколений КЭК как специализированных вычислительных устройств повторяет известную историю поколений ЭВМ.

В своей статье [8] В.П. Тарасенко дал следующую характеристику результатов исследований томских ученых в области корреляционно-экстремальных навигационных систем, выполненных под его руководством и с его участием. Далее приводится цитата из этой статьи с нашей коррекцией ссылок на литературу:

«К числу наших главных достижений в области КЭС можно отнести следующие:

- Сделаны первые в СССР изобретения в области КЭС навигаџии и наведения [9, 10], в которых использовались различные варианты оптических корреляторов, обеспечивающих решение задачи местоопределения в реальном масштабе времени.

- Создана теория, разработаны принциипы построения корреляционно-экстремальных систем навигачии подвижных объектов, использующих пространственно-временную обработку изображений ориентиров различной физической природы.

- Разработаны, изготовлены и испытаны первые в СССР образцы корреляционно-экстремальных координаторов для летательных аппаратов, морских и речных судов, наземных движущихся механизмов, искусственных спутников Земли, использующие радиолокационные датчики земной поверхности и астроориентиры.

- Разработана и внедрена на ряде предприятий машиностроительного профиля корреляционноэкстремальная система зрения промышленных роботов, позволяюшая осуществлять автоматическое распознавание деталей и их ориентирование на сборочном конвейере.

- Развиты приниипы построения и основы теории систем экстремальной радионавигации, обла- 
дающих по сравнению с известными системами рядом преимуществ: в них на единой методологической основе решается проблема борьбы с систематическими и случайными погрешностями, задача комплексного использования радиополей различной природы (гиперболических станций, радиомаяков, сигналов навигационных искусственных спутников Земли).

- Реализована компьютерная технология моделирования, исследования и проектирования сложных информационно-измерительных комплексов для решения задач корреляциионно-экстремальной навигации, пассивной локации и траекторных измерений.

- В начале 70-х годов в Институте оптики атмосферы СО АН СССР (2. Томск) под руководством академика В.Е. Зуева были развернуты крупные исследования по применению корреляциионн-экстремальных методов для анализа характеристик атмосферных неоднородностей и их движений в случае использования датчиков оптического типа. Эти работы завериились созданием лазерных локационных систем измерения скорости ветра на различных высотах [11].

Перечисленные выме результаты описаны в монографиях [7, 11-15], часть из которых академик А.А. Красовский отнес "к числу фундаментальных, не имеющих аналогов за рубежсм"».

К этой цитате добавим, что В.П. Тарасенко организовал проведение в Томске с 11 по 14 сентября 1979 г. первой Всесоюзной конференции по КЭС [16]. Ему принадлежит ключевая роль в судьбе многих ученых и научных коллективов. В.П. Тарасенко подготовил около 50 кандидатов наук, почти двадцать из которых позже стали докторами наук. Это относится и к моей личной судьбе. Моим научным руководителем в аспирантуре ТГУ был д.ф.-м.н. Г.А. Медведев, благодаря его руководству в 1970 г. я стал к.ф.-м.н. В сентябре 1970 г. В.П. Тарасенко основал в ТГУ кафедру теоретической кибернетики и пригласил меня на эту кафедру, а через год, в 1971 г., В.П. Тарасенко был уже в ТИРиЭТе (ТИАСУРе). И за ним потянулись многие, в том числе и автор этих строк. Эта история частично описана выше. Свою докторскую диссертацию я выполнял уже при научной консультации и поддержке В.П. Тарасенко и в 1983 г. стал д.т.н. При его участии в марте 1984 г. состоялась моя встреча с ректором ТИАСУРа И.Н. Пустынским с предложением возглавить одну из кафедр ТИАСУРа. Так, в апреле 1984 г. при непосредственном участии и влиянии В.П. Тарасенко я пришел к заведованию кафедрой АСУ ТИАСУРа (вначале на условиях внешнего совместителя, так как моей основной работой до июня 1984 г. было заведование ЛАОС СФТИ). Подобные истории могли бы вспомнить десятки его учеников и сотрудников. На их жизненные траектории существенное влияние оказал В.П. Тарасенко. Он руководил многими научными коллективами: научными лабораториями (проблемной лабораторией счетно-решающих устройств ТГУ, адаптивных и оптимальных систем СФТИ); кафедрами (теоретической кибернетики ТГУ, ОАСУ ТИАСУР); НИИ (СФТИ (заместитель директора по научной работе, 1965-1970 гг.), НИИАЭМ (директор, 1981-2000 гг.); заместитель председателя ТНЦ СО РАН и директор Отдела проблем информатизации ТНЦ СО РАН (2000-2003 гг.). Под руководством В.П. Тарасенко выполнено несколько десятков крупных НИОКР.

В 1970-х гг. В.П. Тарасенко принимал активное участие в создании автоматизированной системы управления народным хозяйством Томской области (АСУ ТО) и входил в комплексную группу по разработке АСУ ТО при Томском обкоме КПСС, которую возглавлял Ф.И. Перегудов (впоследствии министр высшего образования СССР). После перевода Ф.И. Перегудова в Москву В.П. Тарасенко стал главным конструктором АСУ ТО. В 1985 г. была завершена и сдана в эксплуатацию 2-я очередь АСУ народным хозяйством Томской области. Под его руководством велись работы по автоматизации технологических процессов перекачки нефти по нефтепроводам Сибири и создавались автоматизированные системы информационного обеспечения добычи нефти, в частности, на Лугинецком месторождении.

В 32 городах Сибири были внедрены автоматизированные системы отпуска нефтепродуктов по электронным пластиковым картам. В.П. Тарасенко был инициатором открытия в Томске в 1990 г. первого в стране научно-технологического парка (технопарк), представляющего собой новую эффективную форму территориальной интеграции науки, образования, производства и предпринимательства. Как советник главы администрации Томской области В.П. Тарасенко активно участвовал в разработке и осуществлении концепции государственного эксперимента по развитию Томского научно-образовательного центра.

В заключение обратимся к воспоминаниям друзей Владимира Петровича - выпускников РФФ-57 [5]: они отмечают его остроумие, энергичность, коммуникабельность, общительность, многогранность и талантливость во многом (шахматист, спортсмен, рыбак и бард). Многие вспоминают его песни на музыку известных шлягеров. В воспоминаниях [5] приводится его песня на мотив шлягера «Главней всего погода в доме», в которой есть припев:

\section{Главней всего нам наши встречи, \\ И петь сегодня я хочу: \\ Ещё не срок гасить нам свечи, \\ Задача жить вполне нам по плечу.}

Жизнь продолжается: ученый и организатор науки, талантливый человек Владимир Петрович Тарасенко продолжает жить в своих делах, монографиях, научных статьях, изобретениях и памяти его соратников, учеников, многих других людей, которые его знали. 


\section{Литература}

1. Информационные системы и технологии в экономике и управлении: учеб. / под ред. В.В. Трофимова. - М.: Высшее образование, 2006. - 480 с.

2. Сырямкин В.И., Шидловский В.С. Корреляционно-экстремальные радионавигационные системы. - Томск: Изд-во Том. ун-та, 2010. - 316 с.

3. Профессора Томского университета: биографический словарь. - Т. 3 / С.Ф. Фоминых, С.А. Некрылов, Л.Л. Берцун и др.; отв. ред. С.Ф. Фоминых] ; Том. гос. унт. - Томск: Изд-во Том. ун-та, 2001. -530 с.

4. Профессора Томского государственного университета систем управления и радиоэлектроники / сост. В.В. Подлипенский, Г.С. Шарыгин. - Томск: Том. гос. ун-т систем упр. и радиоэлектроники, 2017. - 200 с.

5. Друзей прекрасные черты. Выпускники РФФ-57 о ТГУ и о себе: сб. статей / сост. Ю.М. Гармаш, В.А. Замотринский, Г.А. Медведев, А.Н. Никифоров, С.Т. Морозов. Томск: Изд-во НТЛ, 2007. - 240 с.

6. Тарасенко В.П. Робот-штурман / В.П. Тарасенко, А.М. Кориков // Наука и жизнь. - 1980. - № 7. - С. 84-90.

7. Белоглазов И.Н., Тарасенко В.П. Корреляционноэкстремальные системы. - М.: Сов. радио, 1974. - 392 с.

8. Страгуль О.Н. Корреляционно-экстремальные системы навигации и локации подвижных объектов / О.Н. Страгуль, В.П. Тарасенко // Автоматика и телемеханика. - 2001. - № 7. - С. 201-210.

9. А.с. СССР № 183625. Устройство для контроля полета летательных аппаратов / В.П. Тарасенко, П.П. Бирюлин // Изобретения, промобразцы, товарные знаки. 1966. - № 23. -2 c.

10. А.c. СССР № 184179. Навигационная система управления по картам местности / В.П. Тарасенко // Изобретения, промобразцы, товарные знаки. -1965 . - № 15. - 3 с.

11. Применение корреляционных методов в атмосферной оптике / В.М. Орлов, Г.Г. Матвиенко, И.В. Самохвалов и др. - Новосибирск: Наука, 1983. - 160 с.

12. Медведев Г.А. Вероятностные методы исследования экстремальных систем / Г.А. Медведев, В.П. Тарасенко. - М.: Наука, 1967. - 456 с.

13. Экстремальная радионавигация / В.И. Алексеев, А.М. Кориков, Р.И. Полонников и др. - М.: Наука, 1978. $280 \mathrm{c}$.

14. Корреляционно-экстремальные видеосенсорные системы для роботов / А.М. Кориков, В.И. Тарасенко, Ю.А. Андреев и др. - Томск: Изд-во Том. ун-та, 1986. $240 \mathrm{c}$.

15. Кориков А.М. Корреляционные зрительные системы роботов / А.М. Кориков, В.И. Сырямкин, В.С. Титов. - М.: Сов. радио, 1990. -264 с.

16. Корреляционно-экстремальные системы управления: доклады Первой Всесоюз. конф. по корреляционно-экстремальным системам, 11-14 сентября 1979 г., г. Томск. - Томск: Изд-во Том. ун-та, 1979. - 318 с.

\section{Кориков Анатолий Михайлович}

Д-р техн. наук, профессор, зав. каф. АСУ ТУСУРа вед. науч. сотр. Томского ф-ла Института вычислительных технологий СО РАН Ленина пр-т, д. 40, г. Томск, Россия, 634050 Тел.: +7 (382-2) 41-42-79

Эл. почта: korikov@asu.tusur.ru
Korikov A.M.

Corypheus of science and technology:

85th anniversary of Vladimir Petrovich Tarasenko

The article is devoted to Vladimir Petrovich Tarasenko (09.12.1934-27.11.2003). On December 9, 2019 Tarasenko V. P. would have turned 85 years old. The main area of scientific interests of V.p. Tarasenko - automatic and automated control of complex systems. He was the first in the USSR to propose the construction principles and to develop the theory of correlation-extreme navigation systems (CENS), using radar maps of the area and which have found their application in aircraft, ships, and ground transport control. In 1993, Vladimir Tarasenko was awarded the State prize of the Russian Federation in the field of science and technology for the development of the construction principles and theory of CENS. Tarasenko took an active part in the creation of the automated management system of the Tomsk region (AMS TR) and was the leader of the project. Under his leadership, the work was carried out on the automation of technological processes for pumping oil through oil pipelines in Siberia, and automated systems for information support of oil production and many other automatic and automated control systems were created.

Keywords: Vladimir Tarasenko, correlation-extreme navigation systems, automatic control systems, automated control systems.

doi: $10.21293 / 1818-0442-2019-22-4-115-124$

\section{References}

1. Informacionnye sistemy i tekhnologii $\mathrm{v}$ ekonomike $\mathrm{i}$ upravlenii [Information systems and technologies in economics and management]. Ed. V.V. Trofimova, Moscow: Vysshee obrazovanie, 2006. 480 p. (in Russ.).

2. Syryamkin V.I., SHidlovskij V.S. Korrelyacionnoekstremal'nye radionavigacionnye sistemy [Correlationextreme radio navigation systems]. Tomsk: Izdatel'stvo Tomskogo universiteta. 2010. 316 p. (in Russ.).

3. Professora Tomskogo universiteta: biograficheskij slovar' [Professors of Tomsk University: a biographical dictionary]. T. 3 / S.F. Fominyh, S.A. Nekrylov, L.L. Bercun and etc., ed. S. F. Fominyh; Tom. gos. un-t. Tomsk: Izdatel'stvo Tomskogo universiteta, 2001. 530 p. (in Russ.).

4. Professora Tomskogo gosudarstvennogo universiteta sistem upravleniya i radioelektroniki [Professors of Tomsk State University of Control Systems and Radioelectronics]. Ed. V.V. Podlipenskij, G.S. SHarygin. Tomsk: Tom. gos. un-t sistem upr. i radioelektroniki, 2017. 200 p. (in Russ.).

5. Druzej prekrasnye cherty. Vypuskniki RFF-57 o TGU i o sebe [Friends are wonderful features. Graduates of the RFF-57 about TSU and about themselves]. Ed. YU.M. Garmash, V.A. Zamotrinskij, G.A. Medvedev, A.N. Nikiforov, S.T. Morozov. Tomsk: Izdatel'stvo NTL, 2007. 240 p. (in Russ.).

6. Tarasenko V.P., Korikov A.M. Robot-shturman [Navigator Robot]. Nauka i zhizn', 1980, № 7, pp. 84-90 (in Russ.).

7. Beloglazov I.N., Tarasenko V.P. Korrelyacionnoekstremal'nye sistemy [Correlation-extreme systems]. Moscow: Sov. radio, 1974. 392 p. (in Russ.).

8. Strangul' O.N.,Tarasenko V.P. [Correlation-Extremal Systems for Navigation and Location of Mobile Objects]. Autom. Remote Control, 62:7 (2001), pp. 1204-1211.

9. Tarasenko V.P., Biryulin P.P. Ustrojstvo dlya kontrolya poleta letatel'nyh apparatov [A device for controlling the flight of aircraft]. A.S. № 183625 po zayavke № 705793/40 s prioritetom ot 17.03 .60 // Izobreteniya, promobrazcy, tovarnye znaki, 1966, № 23 (in Russ.). 
10. Tarasenko V.P. Navigacionnaya sistema upravleniya po kartam mestnosti [Navigation control system on terrain maps]. A.S. № 184179 po zayavke № $710431 \mathrm{~s}$ prioritetom ot 27.03.61 // Izobreteniya, promobrazcy, tovarnye znaki, 1965, № 15 (in Russ.).

11. Orlov V.M., Matvienko G.G., Samohvalov I.V., etc. Primenenie korrelyacionnyh metodov $\mathrm{v}$ atmosfernoj optike [The use of correlation methods in atmospheric optics]. Novosibirsk: Nauka, 1983. 160 p. (in Russ.).

12. Medvedev G.A., Tarasenko V.P. Veroyatnostnye metody issledovaniya ekstremal'nyh sistem [Probabilistic methods for studying extreme systems]. Moscow: Nauka, 1967. 456 p. (in Russ.).

13. Alekseev V.I., Korikov A.M., Polonnikov R.I., etc. Ekstremal'naya radionavigaciya [Extreme radio navigation]. Moscow: Nauka, 1978. 280 p. (in Russ.).

14. Korikov A.M., Tarasenko V.I, Andreev YU.A., and etc. Korrelyacionno-ekstremal'nye videosensornye sistemy dlya robotov [Correlation-extreme video sensor systems for robots]. Tomsk: Izdatel'stvo Tomskogo universiteta, 1986. 240 p. (in Russ.).

15. Korikov A.M., Syryamkin V.I., Titov B.C. Korrelyacionnye zritel'nye sistemy robotov [Correlation visual systems of robots]. Moscow: Sov. radio, 1990. 264 p. (in Russ.).

16. Korrelyacionno-ekstremal'nye sistemy uprav-leniya [Correlation-extreme control systems]. Doklady pervoj Vsesoyuznoj konferencii po korrelyacionno-ekstremal'nym sistemam, 11 - 14 sentyabrya 1979 g., g. Tomsk. - Tomsk: Izdatel'stvo Tomskogo universiteta, 1979. 318 p. (in Russ.).

\section{Anatoly M. Korikov}

Doctor of Engineering Sciences, Professor,

Head of the Department of Automated Control Systems

Tomsk State University of Control Systems and Radioelectronics (TUSUR)

40, Lenin pr., Tomsk, Russia, 634050;

Leading researcher at Tomsk Branch of the Institute of Computing Technologies SB RAS

Phone: +7 (382-2) 41-42-79

Email: korikov@asu.tusur.ru 